J3eA, Journal sur l'enseignement des sciences et technologies de l'information et des systèmes, Volume 2, Hors-Série 2, 16 (2003)

DOI : http://dx.doi.org/10.1051/bib-j3ea:2003616

(C) EDP Sciences, 2003

\title{
Contrôle actif de structures micro-électromécaniques
}

MEMS-based active control of micro and macro-scale structures

P. Vescovo, G. Bourbon, P. Le Moal et P. Minotti

Laboratoire de Mécanique Appliquée R. Chaléat

24 chemin de l'Épitaphe

F-25000 Besançon, France 


\title{
MEMS - BASED ACTIVE CONTROL OF MICRO AND MACRO - SCALE STRUCTURES
}

\author{
Paul Vescovo, Gilles Bourbon, Patrice Le Moal, Patrice Minotti \\ Laboratoire de Mécanique Appliquée R. Chaléat, 24 Chemin de l'Epitaphe 25000 Besançon
}

\begin{abstract}
Résumé : Les technologies silicium sont aujourd'hui connues pour leur double capacité à produire des millions de composants microscopiques au cours d'un seul et même lot de fabrication, et à intégrer des composants électroniques et mécaniques dans des structures monolithiques.

Les réseaux de microactionneurs à base de technologie silicium ouvrent des perspectives nouvelles dans de nombreux domaines. Les dimensions impliquées par de tels dispositifs privilégient naturellement les applications aux échelles millimétrique et/ou micrométrique et concernent, notamment, la manipulation et l'hybridation parallèle et massive des composants sur silicium dans l'industrie électronique. Mais les recherches consacrées aux réseaux de microactionneurs pourraient également avoir des répercussions à l'échelle macroscopique. Les technologies MEMS ouvrent de nouveaux horizons dans le domaine de l'intégration des composants mécaniques, électroniques et sensoriels. Ces technologies émergentes permettent de dupliquer massivement des systèmes micromécaniques complexes à la surface de puces en silicium. Le présent article donne un éclairage particulier sur les futurs systèmes distribués sur silicium et leurs applications potentielles dans le domaine du contrôle actif de structure à base de technologies MEMS. Les projections actuelles montrent que les nouvelles générations de systèmes MEMS distribués trouveront des applications industrielles à des échelles diverses et notamment à l'échelle macroscopique, là où se situent l'essentiel des besoins de l'homme.
\end{abstract}

\section{Introduction}

Although today's structure and product designer have many materials with varied properties to choose from, once a particular material is selected and cut to size, its properties remain fixed. As a consequence, most of individual parts of conventional structures are unable to adapt changing conditions. On the other hand, making the dynamic behavior of matter programmable has the potential to enable "control - centric" products and processes that actively adapt to changing conditions, achieving strength and precision operation through intelligent adjustment of their dynamic behavior [1] [2].

Because the silicon micromachining technology have the potential to integrate both mechanical structures and control circuits, MEMS-based active control of structures therefore appears to be one of the most promising challenges of MST. As an example, numerous projects are being developed in order to enhance active control of super-compact rigid disk drives, using auxiliary IC-processed actuators directly connected to read/write transducers (see section 2). Considerable efforts also began a few years ago so as to demonstrate techniques that will enable distributed MEMS-based arrays of sensors, actuators and computational elements embedded within materials and on surfaces, to enhance and control the behavior of sophisticated structures. Current research includes the development of software and architectures for coordinating the actions of large number of distributed devices. New manufacturing methods are also investigated so as to bring MEMS-style batch fabrication to bear on macro-scale objects.

The futurist ideal system is one in which large numbers of sensors and actuators will be able to work relatively independently to achieve global performance criteria such as structural stability and mechanical modulation of surface properties. As one of the steps towards autonomous distributed systems, the following gives the current state of the art in the area of distributed IC-processed devices, with a special emphasis on microactuators and their control strategies.

\section{Active control of read/write magnetic head}

IC-processed actuators are expected to provide high-bandwith servo-controlled precision mechanisms in order to acquire, store, distribute and process information at previously unimaginable speed and volume [3]. High-performance ICprocessed mechanical systems are being designed in order to facilitate the introduction of a new generation of super-compact computer peripheral devices. Angular actuation is widely selected (e.g. against linear actuation), because such a configuration allows high lateral stiffness, minimizing the sensitivity of the MEMS-based servo-system to shock loading in the plane of the disk [4]. In addition, electrostatic actuation appears to be particularly efficient compared with other actuation approaches, because it allows both high accuracy and high-bandwith operation as well as intrinsic capacitive measurement of displacement.
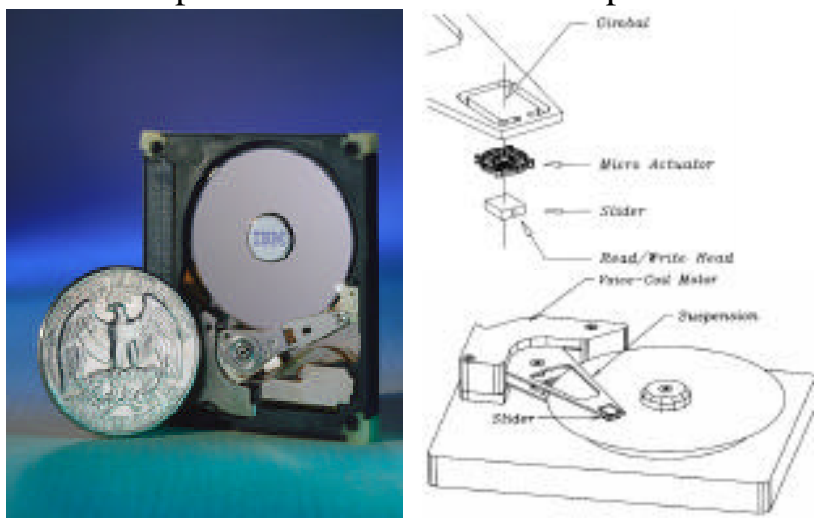

Figure 1. (a) Tiny disk drive after IBM, http: //www.storage.ibm.com. (b) Servo positioning, mechanism scheme of a magnetic disk drive including an IC-processed actuator between the slider and the gimbal. 


\section{Parallel manipulation using mechanical modulation of surface properties}

\subsection{Concept of Distributed Microactuators}

Most of prospective applications of IC-processed actuators presently deal with optics, transportation and aerospace, robotics chemical analysis systems, biotechnologies, medical engineering and microscopy using scanned micro probes [5]. These applications have a common feature in that only very light objects such as mirrors, magnetic heads, valves, cells and microprobes are manipulated and that little physical interaction with the external environment is necessary. The main reason is that most of present micrometer size IC-processed actuators are still primitive and large forces cannot be transmitted to the external world.

Although the small size of IC-processed components is a very distinctive feature of the MEMS technology, it has other, may be even more attractive features. Thus, a decisive advantage offered by the silicon micromachining technology is the possibility of implementing sensors and actuators within interactive arrays. Cooperative work of many actuation cells can perform a large task, even one single IC-processed actuator can only produce unusable force or perform insignificant motion. Therefore, in addition to miniaturization, the concept of multiplicity appears to be another key to successful microsystems.

The third key to successful microsystems deals with the integration of microelectronics which is also essential for distributed microactuators to cooperate with each other and to perform a given macroscopic task.

Before discussing sophisticated autonomous distributed systems that will integrate many smart modules on a wafer without assembly, the following analyses former investigations on arrayed microactuators for conveyance systems.

\subsection{Concept of Programmable Vector Fields using IC- Processed Micromanipulators}

Former IC-processed micromanipulators involving actuator arrays have been investigated in Japan [6]. The key idea was to coordinate simple motions of many microactuators so as to obtain significant macroscopic work out of distributed IC-processed actuators. As shown in Fig. 1, earlier investigations focused on conveyance systems using respectively thermally driven cantilevers and air flow systems [7] [8].

Massively-parallel microfabricated motion pixels has been the first step towards autonomous distributed systems. Investigations are now moving to new automation devices allowing controlled self-assembly of parts via electromechanical modulation of surface properties. Using IC-processed sensors and actuators, programmable vector fields can be theoretically used to control a variety of flexible planar part feeders that will be needed in the microelectronics industry [9].

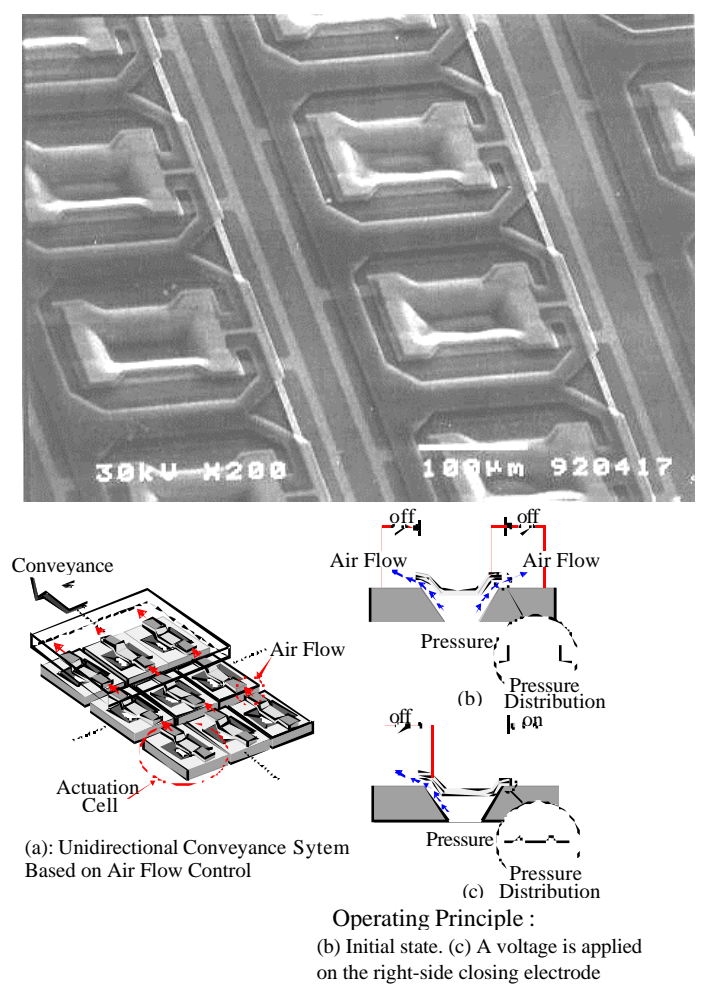

Figure 2(a) Air-flow conveyance system involving distributed nozzles. After [7].

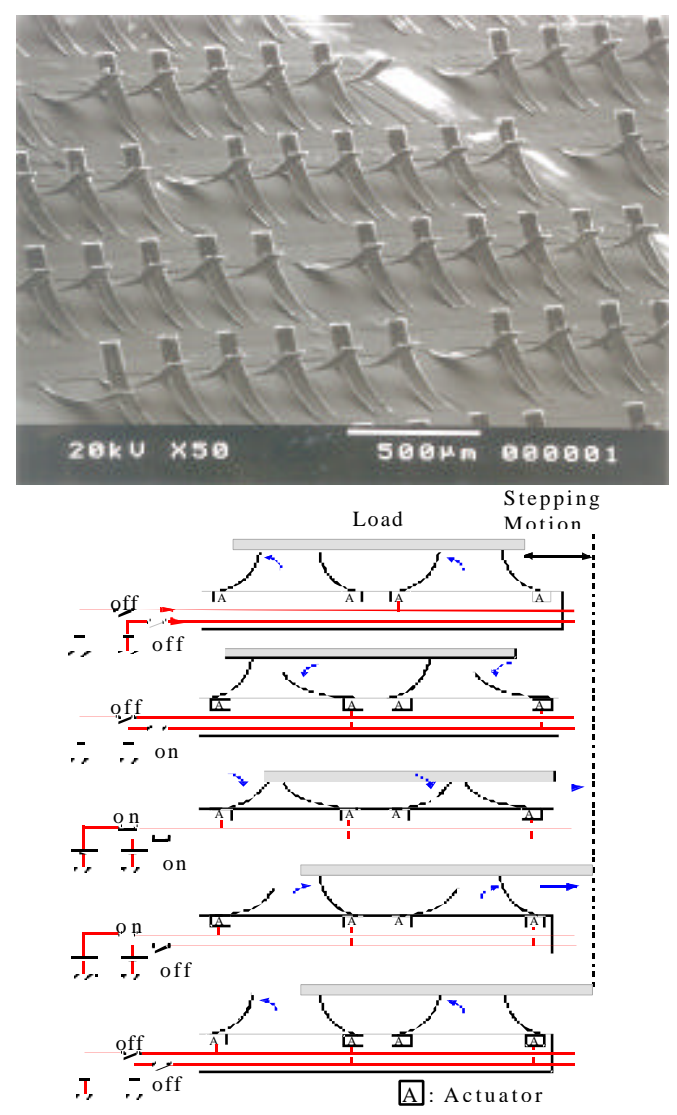

Figure 2(b) Ciliary motion system using thermal actuation. After [8]. 
Figure 3 gives an illustration of the principle of tactile shape recognition using contact detection of various manipulated parts [10]. However, sophisticated systems combining many IC-processed sensors and actuators are yet challenging. Thus, recent attention focused on sensor-less strategies such as illustrated in Fig. 4 [11].

a)
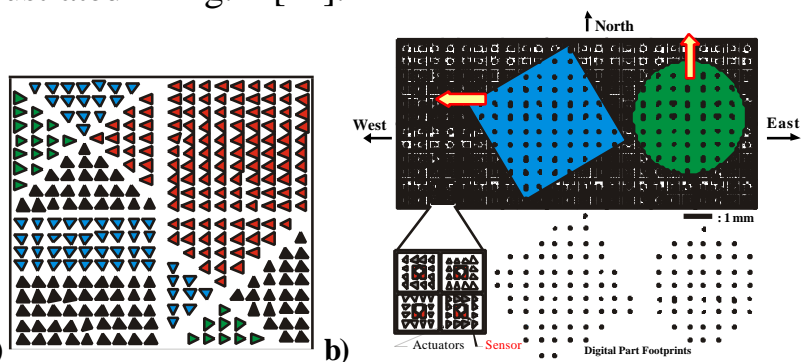

Figure 3. (a)Concept of multidirectional motive surfaces using modern array technologies and (b)principle of tactile shape recognition using contact detection of manipulated parts. After [10].

a)

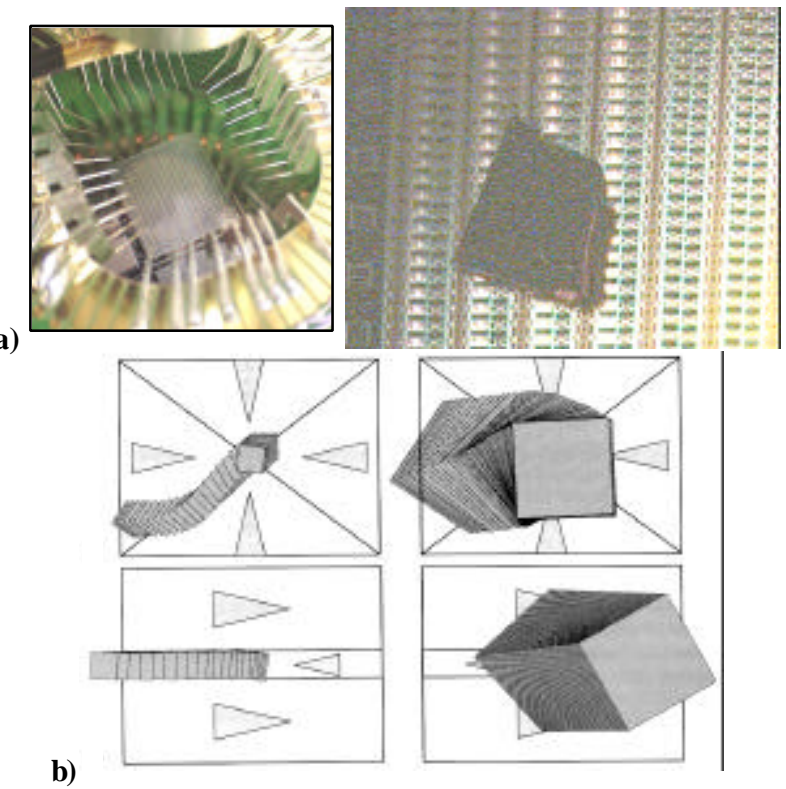

Figure 4. (a) Micromanipulator involving distributed IC-processed electrostatic oscillators [9]. (b)Sensor-less sorting strategy using force vector fields: parts of different sizes are first centered and subsequently separated depending on their size. After Böhringer et al. [11].

When a part is placed on top of an actuator array, the programmed vector field induces a force and moment upon it. Then, by chaining together sequences of local vector fields, the part is conveyed until the desired final state is reached. Assuming the part may come to rest in a dynamic equilibrium state over time, the resulting strategy requires no sensing and enjoy efficient planning algorithms [11].

As a second step towards fully integrated part feeders, the first micromachined IC-processed actuator array with on-chip CMOS circuitry was recently developed at the Department of Electrical Engineering of Stanford University. The array is composed of an $8 \times 8$ array of elementary motion pixels, each having four orthogonally oriented actuators, in an overall die size of $9.4 \times 9.4 \mathrm{~mm}$ (see Fig. 5) [12].

The polyimide-based ciliary actuators were fabricated directly above the selection and drive circuitry. As shown in Fig. 5, the array has been successfully programmed to do simple linear and diagonal translations as well as rotating-field manipulations. The tasks were demonstrated using flat silicon pieces of various shapes having either 0.5 and $0.1 \mathrm{~mm}$ thickness.
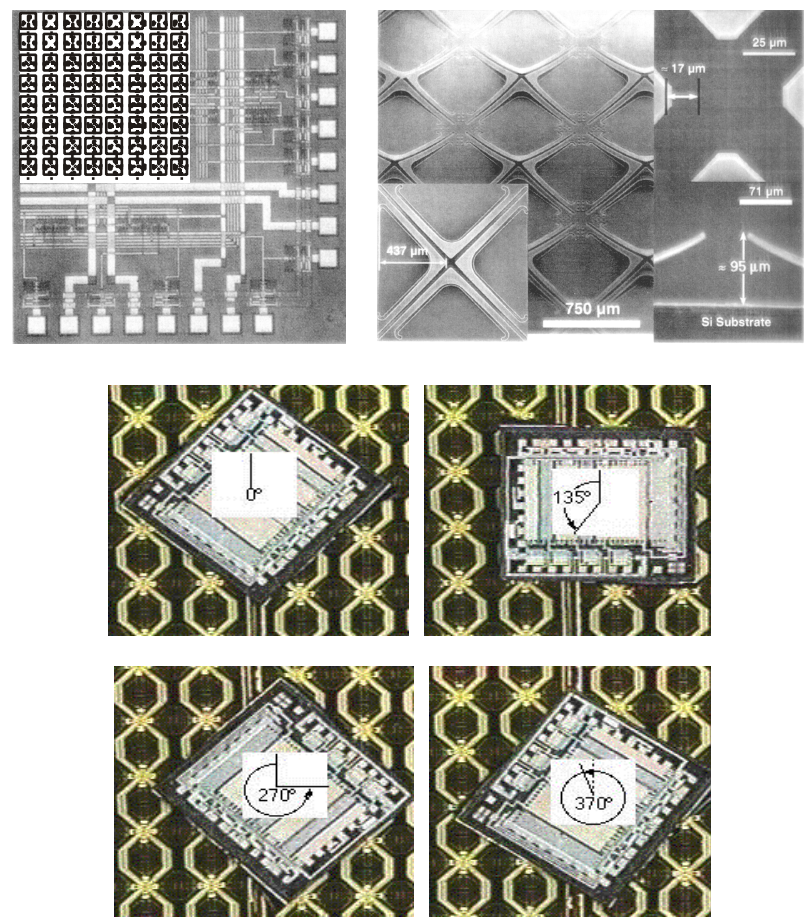

Figure 5. First CMOS-integrated actuator array. After [11]

\section{Towards MEMS-based control of acoustical impedance}

There appear to be a number of applications in acoustics that could benefit from MEMS-based electromechanical transducers which efficiently radiate acoustic waves into an adjacent medium, and comes in the form of a flexible sheet, that can be bounded to the surface of macro-scale structures [13] [14]. In the case were the medium is a gas, such as air, examples of potential applications include active noise control, acoustic flow control and specialty audio systems such as CMOS-MEMS membranes for audiofrequency acoustic radiation [15].

As a first step towards MEMS-based active control of noise, Fig. 6 shows an experimental platform which integrates a vibrating plate isolated with an array of surface-micromachined acoustic transducers. The transducers have been designed so that the radiated pressure in far field would be significantly decreased at frequencies on the order of a few $\mathrm{kHz}$. The vibrating plate is made of a 500 micrometer thick silicon wafer that is clamped on a $\phi 50 \mathrm{~mm}$ circle. The 
obtained circular plate is then sustained in transverse vibration through input external forces that are supplied with a driving frequency set at the first outof-plane resonance frequency of the clamped silicon plate. Thus, the vibrating plate works as a single crystal silicon resonant membrane which radiates significant acoustic pressure in the audible range.

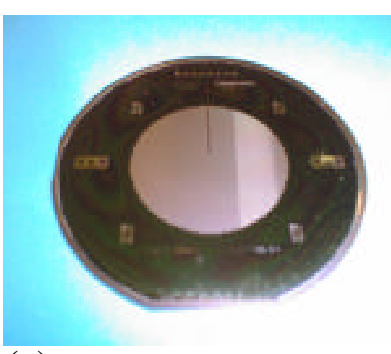

(a)

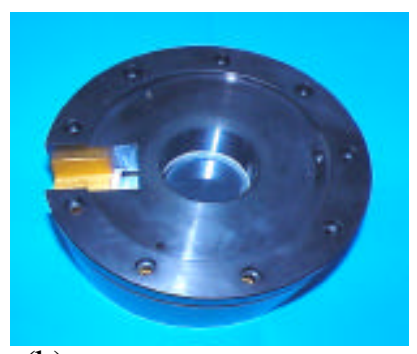

(b) (c)
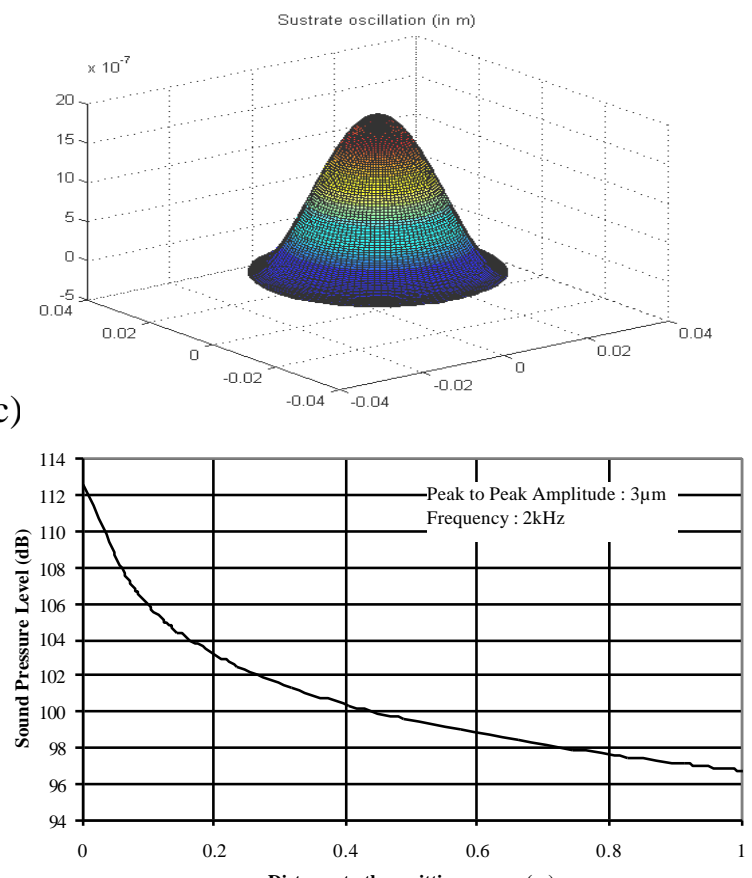

(d)

Figure 6. MEMS-based active control of noise using surface-micromachined array of polysilicon acoustic transducers. (a) and (b) Photographs showing respectively the silicon wafer before and after clamping into the metallic frame. The array of $\mathbf{8 0 0 0}$ acoustic transducers is located at the center of the wafer. (c) and (d) Acoustic radiation of the uncontrolled silicon membrane which is expected to be killed through open-loop control of MEMS-based transducers. After LMARC/ IMFC-Besançon (France).

As shown in Figs. 6 (c) and (d), with maximal peak-to-peak oscillations of 3 microns at the center of the membrane, the radiated acoustic pressure level is on the order of $100 \mathrm{~dB}$ at $2 \mathrm{kHz}$ driving frequency which is closed to the resonance frequency of the silicon membrane.

The MEMS-based acoustic transducer array that is distributed over the emitting surface of the silicon membrane combines 8000 parallel plate polysilicon capacitors. Quasi-static control of the out-of-plane motion of the elementary acoustic transducers can be achieved from dc up to $15 \mathrm{kHz}$, with an ac amplitude response on the order of a few microns under low driving voltage (e.g. roughly 20 Volts). So, even if out-of-plane oscillations are still quite restricted, parasitic acoustic pressure levels on the order of 100 $\mathrm{dB}$ at $2 \mathrm{kHz}$ are expected to be actively killed, by controlling the local motion of each MEMS-based acoustic transducer. In practice, the driving annular electrodes deposited over the silicon wafer (e.g. the emitted surface), are supplied in such a way that the absolute displacement of acoustic transducers becomes nearly negligible, whatever the local displacement $\delta$ of the vibrating silicon substrate.

Industrial applications involving MEMS-based acoustic transducers are mainly expected in aeronautics and car industry so as to significantly reduce parasitic acoustic radiation of aircraft reactors and internal combustion engines. Similar developments are also expected in the field of MEMSbased flow sensors and actuators for drag reduction in next generation aircraft and spacecraft.

\section{Towards micromechanical flying insects}

The high level of interest in developing new classes of micro air vehicles (MAV), such as artificial insects, is the result of the nearly simultaneous emergence of their technological feasibility and an array of new needs in environment. Technological feasibility of artificial insects follows from recent advances in MEMS technology that allow the design of processes and systems combining microelectronics components with comparably-sized mechanical elements [16]. The arsenal of well established microfabrication techniques provides a high degree of optimism with respect to integrated propulsion systems inspired from biological mechanisms [17] [18]. Other maturing microsystems such as tiny CCDarray cameras, small infra-red sensors, chip-sized substance detectors and thin film solar cells, also contribute to the emerging interest in designing very small flight vehicles that mimic biological structures.

Artificial insects are yet challenging. Several enabling technologies will be simultaneously needed in order to successfully integrate functional blocks such as propulsion and power system, sensors and processing units, as well as air frame structure and communication units into MAV systems. In addition, innovative solutions and original designs will be needed to solve aerodynamics and control, propulsion and power as well as navigation and communication [16].

As a first step towards MEMS-based artificial insects, Fig. 7 shows first-generation prototypes of silicon-based ornithopters involving flapping wing propulsion systems that mimic nature. Four degrees of freedom in each wing are used to achieve flight in nature: flapping, lagging, feathering and spanning 
[19]. However, not all flying animals implement all of these motions. Thus, most insects do not use the spanning technique (e.g. successive expanding and contracting of the wingspan). In addition, insects with low wing beat frequencies on the order of a few tens $\mathrm{Hz}$, generally have restricted lagging capabilities (e.g. forward and backward wing motion parallel to the flying body). Thus, flapping flight is possible with only to degrees of freedom that respectively satisfy flapping and feathering.

The MEMS-based wings shown in Fig. 39 have been designed so as to allow both flapping (e.g. angular movement about an axis in the direction of flight), and feathering (e.g. angular movement about an axis in the center of the wing which tilts the wing to change its angle of attack). So when they are coordinated, these two degrees of freedom are expected to provide lift not only on the down stroke, but also on the up stroke, as it is the case for flying insects.
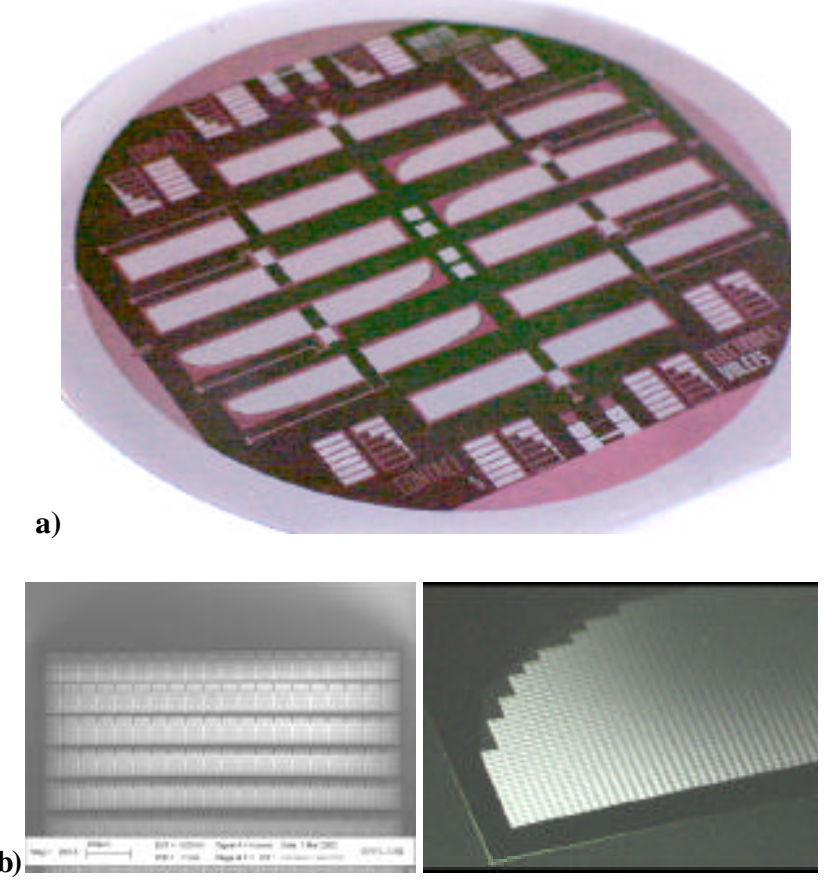

Figure 7. (a) Silicon-based ornithopters. four inches SOI wafer including various wings covered with distributed microactuators,

(b) SEM micrograph and 3D video image showing arrayed actuators distributed over the wing's surface. After LMARC/ IMFC-Besançon (France).

Figure. 8 shows a SEM micrograph of a wing that has been recently released from the silicon wafer. The wing is going to be actuated through the 20,000 elementary actuation cells that are distributed over the upper surface of the centimeter scale single crystal silicon structure. According to the micrometer thickness of both the single crystal silicon wing (e.g. 5 to 10 microns), and the distributed polycrystalline silicon actuators, the overall mass of the flapping wing system is restricted to a few milligrams. The design specifications of the proposed MEMS-based flapping system are summarized in Table I.

\begin{tabular}{ll}
\hline Wingspan lateral dimensions & $\sim 40 \times 10$ millimeters \\
$\begin{array}{l}\text { Wingspan structural thickness } \\
\text { Distributed actuation cells }\end{array}$ & $\sim 5$ to 10 microns \\
per wing & $\sim 20,000$ \\
Overall mass of the flapping & \\
wing propulsion system & $\sim 1.2$ milligram \\
$\begin{array}{l}\text { Wingbeat frequency } \\
\text { Flapping amplitude range }\end{array}$ & $\sim 30$ to $50 \mathrm{~Hz}$ \\
$\begin{array}{l}\text { Expected on-board energy } \\
\text { density (Lithium Battery) }\end{array}$ & $\sim+/ 50^{\circ}$ \\
\end{tabular}

TABLE 1. Design specifications of the MEMS-based flapping wing system shown in Fig. 6

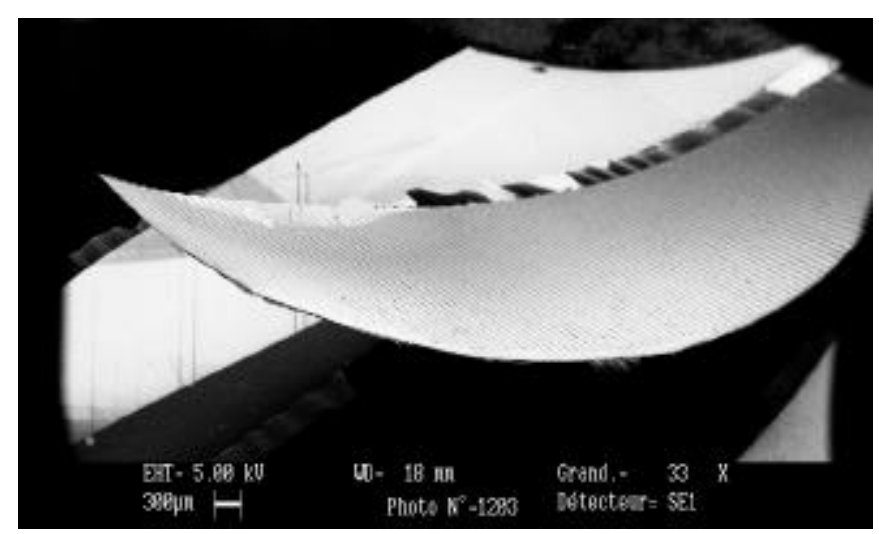

Figure 8. First released prototype of a self-actuated flapping wing involving 20,000 distributed actuation cells. After LMARC/ IMFC-Besançon (France).

\section{Conclusion}

Historically, conventional ultra-precision toolmachining historically made significant contributions to microsystems technology (MST), but the speed of progress was relatively slow until IC-technologies were introduced to the fabrication process of mechanics. Also, MEMS technology, which basically makes use of the tools of microelectronics, gave rise to a growing motivation for MST. According to remarkable progresses briefly summarized in this contribution, MEMS technology has recently exhibited the potential to integrate silicon-based mechanical structures, CMOS circuits as well as fluidic and photonic devices with very small dimensions on a common substrate. It is thus clear that MST and MEMS will have a profound influence in many areas dealing, in particular, with mechanical engineering.

Remarkable progresses that have been achieved from early 1990's in microsystem technology (MST), will certainly result in a growing involvement of mechanical engineers in the field of MEMS-based active control of micro and macro-scale structures. So far, electrical engineers devoted themselves in MEMS processes and materials, but the involvement of mechanical engineers becomes obviously essential for inventing new actuation mechanisms and improving 
design tools towards MEMS-based smart structures. It will be important, and even decisive for the success of MST, that in design of mechanical structures, the means offered by the MEMS technology will be adequately applied. Miniaturization of systems using linear reduction of macroscopic scale structures would not adequately take into account both scaling effects and potentials of the MEMS technology. Additionally, it would not be reasonable to use MEMS technology to produce conventional components on a reduced scale, because taking advantage of batchwise manufacture only, would not be wholly satisfactory.

Mechanical engineers will thus have to learn MST and MEMS before investigating completely new design strategies that will optimize the advantages offered by MEMS technology. MEMS-based active control of macro-scale structures using bottom-up design strategies will be clearly of particular interest (e.g. mainly because humans are living on the macroscopic scale), and will probably decide whether or not MST and MEMS can gain ground on the market over conventional technologies. The proposed approach to smart structure design using MEMS technology is dedicated to various readers. To students and those who are not familiar with MEMS, it is expected to help them to better understand the meanings of miniaturization and integrated systems. To experts in mechanical engineering, it finally provides an insight on how both MEMS-based structures and fabrication processes should be simultaneously designed to successfully integrate functional blocks into MEMS-based responsive systems for active control of micro and macro-scale structures.

\section{References:}

[1] Minotti, P. (2002), Responsive systems for active vibration control, Nato Science Series, Kluwer Academic Publishers, 325-377.

[2] Berlin, A.A. (1997) MEMS based active control of macroscale objects, Semiannual Technical Progress Report $\mathrm{n}^{\circ}$ DABT63-95-C-0025, Defense Advanced Research Project Agency.

[3] Temesvary, V., Wu, S., Hsiech, W.H., Tai, Y.C. and Miu, D.K. (1995) Design, fabrication and testing of silicon microgimbals for super-compact rigid disk drives, Journal of Microelectromechanical Systems, 4, 18-26.

[4] Horsley, D.A., Cohn, M.B., Singh, A., Horowitz, R. and Pisano, A. (1998) Design and fabrication of an angular microactuator for magnetic disk drives, Journal of Microelectromechanical Systems 7, 141-148.

[5] Fujita, H. (1996) Future of actuators and microsystems, Sensors \& Actuators A, 56, 105-111.

[6] Fujita, H., Ataka, M. and Konishi, S. (1996) Group work of distributed microactuators, Robotica, 14, 487-492.

[7] Ataka, M., Omokada, A., Takeshima, N. and Fujita, H. (1993) Polyimide bimorph actuators for a ciliary motion system, Journal of Microelectromechanical Systems 2, 146-150.

[8] Konishi, S. and Fujita, H. (1994) A conveyence system using air flow based on the concept of distributed micro motion systems, Journal of Microelectromechanical Systems 3, 54-58.

[9] Böhringer, K.F., Donald, B.R., Mihailovich, R. and Macdonald, N.C. (1994) A theory of manipulation and control for microfabricated actuator arrays, Proceedings on Microelectromechanical Systems, Oiso (Japan), 102-107.

[10] Bourbon, G., Minotti, P., Hélin, P. and Fujita, H. (1999) Toward smart surfaces using high-density arrays of siliconbased mechanical oscillators, Journal of Intelligent Material Systems and Structures, 10, 534-540.

[11] Böhringer, K.F., Donald, B.R., Mihailovich, R. and Macdonald, N.C. (1994) Sensor-less manipulation using massively parallel microfabricated actuator arrays, Proceedings of IEEE International Conference on Robotics and Automation, San Diego (US), 826-833.

[12] Suh, J.W., Darling, R.B., Böhringer, K.F., Donald, B.R., Baltes, H. and Kovacs, G.T.A. (1999) CMOS integrated ciliary actuator array as a general purpose micromanipulation tool for small objects, Journal of Microelectromechanical Systems 8, 483-496.

[13] Whitehead, L.A. and Bolleman, B.J. (1995) Microstructured elastomeric electromechanical film transducer, Journal of Acoustical Society of America, 103, 389-395.

[14] Collet, M. and Minotti, P. (2001) Toward acoustical impedance control of vibrating walls using silicon-based active skin, Proceedings of the $5^{\text {th }}$ SIAM Conference on Control and its Applications, San Diego (US), P. 241.

[15] Neumann, J.J. and Gabriel, K.J. (2002) CMOS-MEMS membrane for audio-frequency acoustic actuation, Sensors \& Actuators A, 95, 175-182.

[16] McMichael, J.M. and Francis, M.S. (1997) Micro air vehicles: toward a new dimension in flight, http://www.darpa.mil/tto/mav

[17] Fearing, R.S., Chiang, K.H., Dickinson, M.H., Pick, D.L., Sitti, M. and Yan, J. (2000) Wing transmission for a micromechanical flying insect, Proceedings of IEEE International Conference on Robotics and Automation, San Francisco (US), 1509-1516.

[18] Pornsin-sirirak, T.N., Lee, S.W., Nassef, H., Grasmeyer, J., Tai, Y.C., Ho, C.M. and Keennon, M. (2000), $13^{\text {th }}$ IEEE International Conference on Microelectromechanical Systems, Miyazaki (Japan), 799-804.

[19] Azuma, A. (1992) The biokinetics of flying and swimming, Springer Verlag-Tokyo. 
